\title{
PEMBERDAYAAN MASYARAKAT LOKAL DALAM PEMANFAATAN ALGA COKELAT (SARGASSUM sp.) SEBAGAI PEWARNA ALAMI MIE ACEH DI KOTA MEULABOH
}

\section{THE EMPOWERMENT OF LOCAL COMMUNITY IN UTILIZATION OF BROWN ALGAE (SARGASSUM SP.) AS NATURAL COLOUR OF ACEH NOODLE AT MEULABOH CITY}

\author{
Mohamad Gazali ${ }^{1}$, Zuriat ${ }^{2}$ \\ ${ }_{1}^{1}$ Prodi IImu Kelautan Fakultas Perikanan dan IImu Kelautan Universitas Teuku Umar \\ 2Prodi Perikanan Fakultas Perikanan dan IImu Kelautan Universitas Teuku Umar \\ Korespondensi: mohamadgazali@utu.ac.id/Mobile Phone :+681343240218
}

\begin{abstract}
ABSTRAK
Rumput laut merupakan salah satu potensi biodiversitas hayati laut yang memberikan nilai tambah (value added) dalam bidang farmasi dan kosmetika. Tujuan kegiatan pengabdian kepada masyarakat ini adalah untuk meningkatkan pemahaman dan keterampilan tentang pemanfaatan rumput laut asal Barat Selatan (Barsela) Aceh sebagai pewarna alami mie Aceh. Kegiatan pengabdian dilaksanakan pada bulan Juni 2019 yang bertempat di Jalan Gajah Mada Kecamatan Djohan Pahlawan Kabupaten Aceh Barat Propinsi Aceh. Tahapan pelaksanaan meliputi pengambilan bahan baku, uji coba penggunaan pewarna alami dari rumput laut dan sosialisasi dan pelatihan. Kegiatan pengabdian kepada masyarakat yang melibatkan mitra produsen agar dapat menciptakan inovasi-inovasi yang berguna bagi masyarakat lokal dengan memanfaatkan potensi sumberdaya kelautan sebagai sumber pangan dan obat-obatan.
\end{abstract}

Kata kunci: Rumput laut, Pemberdayaan, Pewarna Alami, Mie Aceh

\begin{abstract}
The seaweed are one of the potency of the marine biodiversity that give value added in pharmacy and cosmetic. The aim of this community empowerment is to increase the understanding and skill regarding the utilization of seaweed from South West Aceh as natural colour of Aceh Noodle. The community empowerment was conducted on July 2019 that located in Jalan Gajah mada Djohan Pahlawan District West Aceh Regency. The stage of activity including taking raw material, try and error in using natural colour from seaweed and socialization and training. The empowerment community that involved the producer partner in order to create a lot of innovations that useful for local community with utilizing the marine resources potency as foodstuff source and medicine.
\end{abstract}

Keywords : Seaweed, Empowerment, natural colour, Aceh Noodle

\section{PENDAHULUAN}

Indonesia dikaruniai oleh potensi sumberdaya laut yang pesat yang terbentang dari Sabang sampai Merauke. Salah satu potensi sumberdaya lautnya adalah rumput laut yang berjumlah \pm 782 jenis (ekspedisi laut sibolga 1899-1990 oleh Van Bosse). Spesies rumput laut laut yang paling banyak tersebar di perairan Indonesia adalah Gracilaria, Gelidium, Eucheuma, Hypnea, Sargassum, dan Turbinaria yang dapat yang dapat dimanfaatkan dalam berbagai bidang industri (KKP-RI, 2008).

Rumput laut adalah salah satu komoditas perikanan yang memiliki nilai ekonomis sebagai bahan makanan dan keperluan industri (Critchley et al., 2006). Pemanfaatan rumput laut sebagai bahan makanan, obat-obatan dan keperluan industri 
tergantung pada senyawa yang terkandung didalamnya (Widyastuti, 2009). Berdasarkan hasil survey bahwa sepanjang pesisir Barat Selatan (BARSELA) Aceh memiliki keanekaragaman rumput laut yang cukup tinggi. Kami peneliti melaksanakan kegiatan pengabdian kepada masyarakat dengan menerapkan IPTEK dari rumput laut. Kegiatan ini merupakan kegiatan pengabdian berbasis riset yang diimplemenrasikan kepada masyarakat lokal. Salah satu IPTEK yang diterapkan dengan memanfaatkan potensi laut yakni pigmen rumput laut yang dijadikan sebagai alternatif pewarna kimia pada Mie Aceh. Oleh karena, peneliti berusaha menemukan inovasi baru yang diimplementasikan kepada masyarakat agar dapat meningkatkan kesehatan masyarakat yang baik.

\section{Permasalahan}

Sebagian besar produsen mie Aceh menggunakan pewarna sintesis disebabkan oleh faktor harga yang lebih murah, digunakan hanya dapat kadar/dosis yang kecil sudah memperlihatkan warna orange kekuningan seperti Mie Aceh. Akan tetapi dampak penggunaan pewarna sintesis (kimia) secara terus-menerus berdampak negatif pada kesehatan tubuh. Hal ini menjadi permasalahan utama dalam masyarakat yang butuh pemecahan masalah. Dengan adanya kegiatan pengabdian kepada sintesis ini dapat memberikan peluang bagi masyarakat lokal untuk mengganti pewarna sintetik menjadi pewarna alami yang berasal dari rumput laut laut.

\section{Tujuan Kegiatan}

Tujuan kegiatan pengabdian kepada masyarakat ini adalah untuk memberikan pemahaman dan pengetahuan tentang pemanfaatan potensi rumput laut sebagai pewarna alami pengganti pewarna sintesis untuk Mie Aceh. Hal ini bertujuan agar produsen mie Aceh dapat mengalihkan pemakaian pewarna sintesis secara berangsurangsur dengan pewarna rumput laut laut. Disisi lain, dengan adanya pemanfaatan secara berkelanjutan.

\section{METODE PELAKSANAAN \\ Waktu dan Lokasi}

Kegiatan pengabdian kepada masyarakat dilaksanakan pada bulan Juni 2019 yang bertempat di Jalan Gajah Mada Kecamatan Djohan Pahlawan Kabupaten Aceh Barat Propinsi Aceh.

\section{Metode}

Metode pelaksanaan kegiatan pengabdian kepada masyarakat yakni menggunakan teknik penyuluhan secara langsung yaitu melakukan sosialisasi dan pelatihan penggunaan pewarna alami kepada mitra PKMS yakni produsen mie Aceh. Mitra PKM ini adalah Aneka Mie milik Bapak Syafrinizal. Beliau mengelola mie Aceh ini sudah puluhan tahun yang dibantu dengan sanak famili serta beberapa orang pekerja. Peneliti dan mitra bekerjasama untuk menciptakan pewarna alami yang berasal dari potensi lokal Aceh Barat yaitu rumput laut. Adapun langkah-langkah program pengabdian kepada masyarakat ini adalah sebagai berikut: 


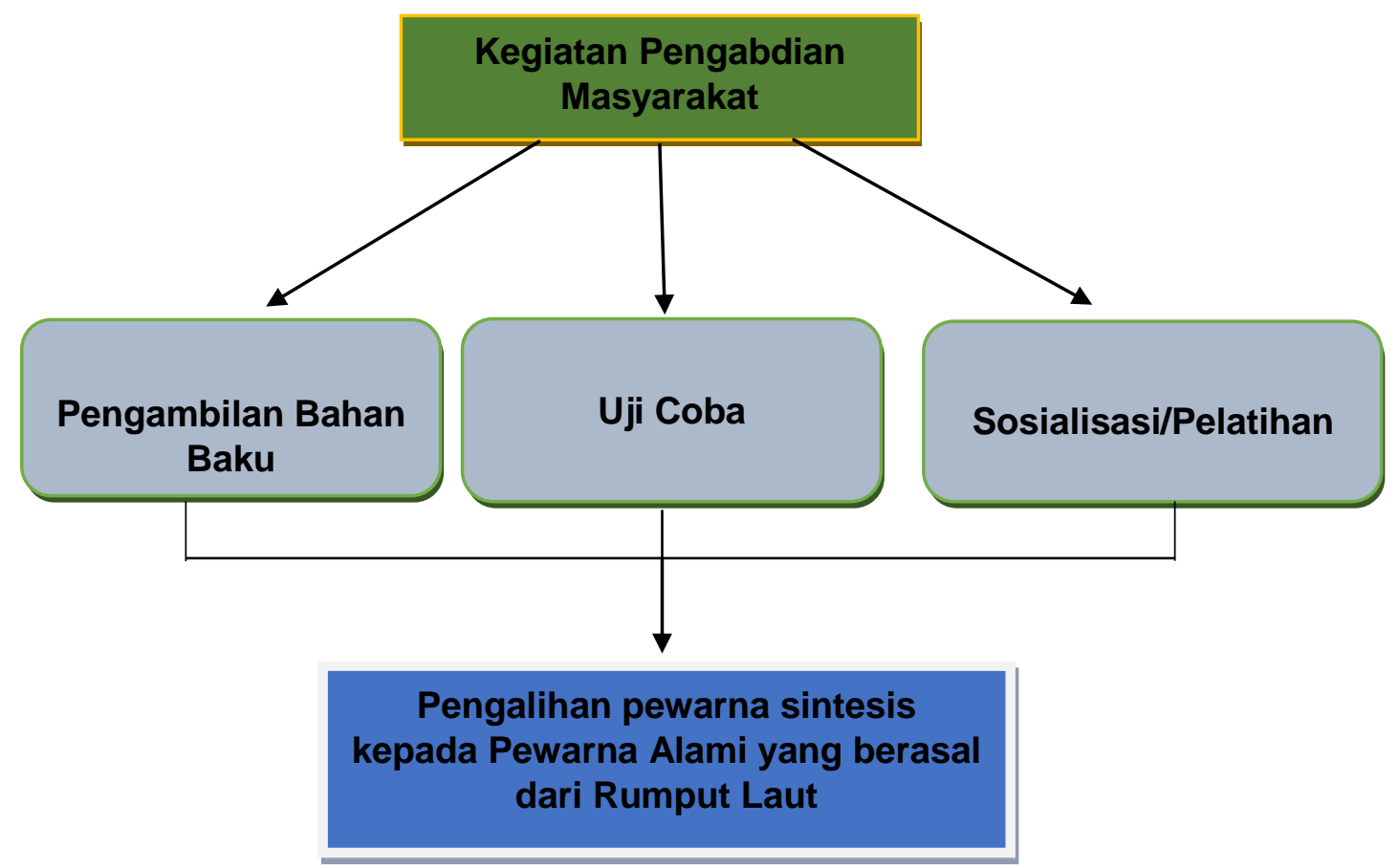

Gambar 1. Tahapan-Tahapan Pelaksanaan Kegiatan PKM

\section{HASIL DAN PEMBAHASAN}

\section{Pengambilan Bahan Baku Rumput Laut}

Langkah awal yang dilakukan yaitu mencari dan mengumpulkan bahan baku rumput laut meliputi alga cokelat dan alga hijau. Pengambilan rumput laut dilakukan di pesisir Barat Selatan Aceh. Beberapa jenis rumput laut yang dijadikan bahan baku pewarna alami meliputi alga cokelat berupa Sargassum sp, Padina australis dan alga hijau berupa Chaetomorpha crassa, Enteromorpha sp, Caulerpa racemosa (Gambar 1).

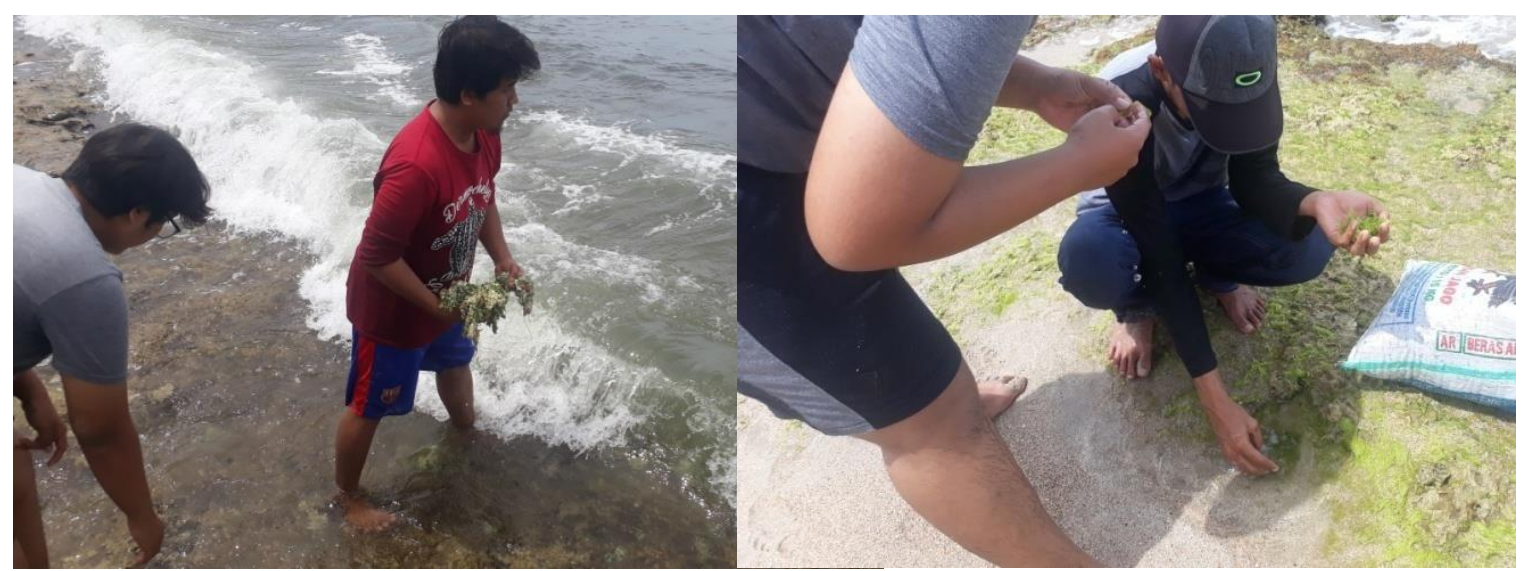

Gambar 2. Pengambilan Bahan Baku Rumput Laut 


\section{Kegiatan Uji Coba}

Langkah berikutnya, kami melaksanakan uji coba rumput laut sebagai pewarna alami Mie Aceh. Sebelumnya, rumput laut segar dikeringkan dengan cara dianginanginkan selama 3-4 hari kemudian digiling sehingga menjadi serbuk simplisia. Dalam pembuatan pigmen rumput laut menghasilkan berbagai warna pada Mie Aceh. Pada pelaksanaan uji coba pewarna pigmen rumput laut ini peneliti mengukur takaran ekstrak rumput laut sebanyak 200 gram dicampur $1 \mathrm{~kg}$ tepung terigu kemudian dicampur dengan berbagai komposisi lainnya kemudian dimasukkan ke dalam mesin pengolah mie Aceh sehingga terbentuklah mie Aceh. Setelah itu mie tersebut direbus dengan air mendidih selama $5 \pm$ menit dan dianginkan menggunakan kipas angin.
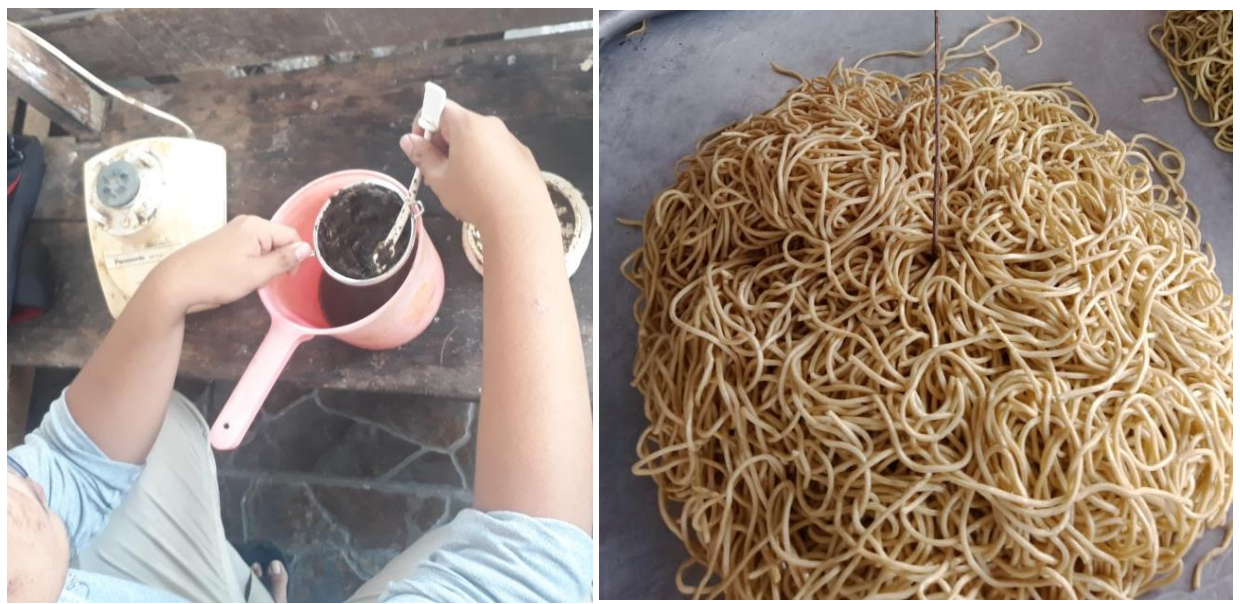

Gambar 3. Proses uji Coba Pewarna Alami Rumput Laut

\section{Penyuluhan dan Pelatihan}

Peneliti melaksanakan penyuluhan kepada masyarakat lokal tentang manfaat pewarna alami rumput laut sebagai bentuk pengabdian kepada masyarakat. Dalam kegiatan tersebut, peneliti melaksanakan praktek yang melibatkan masyarakat, dosen dan mahasiswa. Dalam program, kegiatan Pengabdian ini juga dihadiri oleh Dekan Fakultas Perikanan dan IImu Kelautan Universitas Teuku Umar. Dalam penyuluhan tersebut diajarkan cara menggunakan pewarna alami rumput laut pada pembuatan mie Aceh. Masyarakat lokal sangat antuasias mengikuti program pengabdian kepada masyarakat.

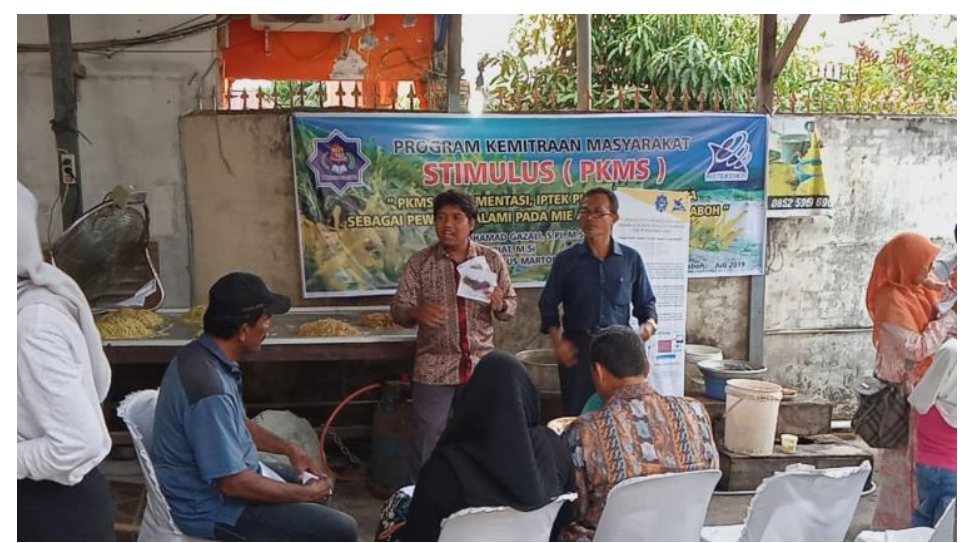

Gambar 4. Kegiatan Penyuluhan kepada masyarakat dan Mitra PKM 
Output kegiatan penyuluhan yaitu adanya peningkatan pengetahuan dan keterampilan dalam memanfaatkan pewarna alami yang berasal dari rumput. Selain itu, produsen dapat mengalihkan penggunaan pewarna sintesis kepada pewarna alami yang berasal dari rumput laut. Produk mie Aceh yang dihasilkan dengan warna cokelat, kuning dan hijau (Gambar 5).
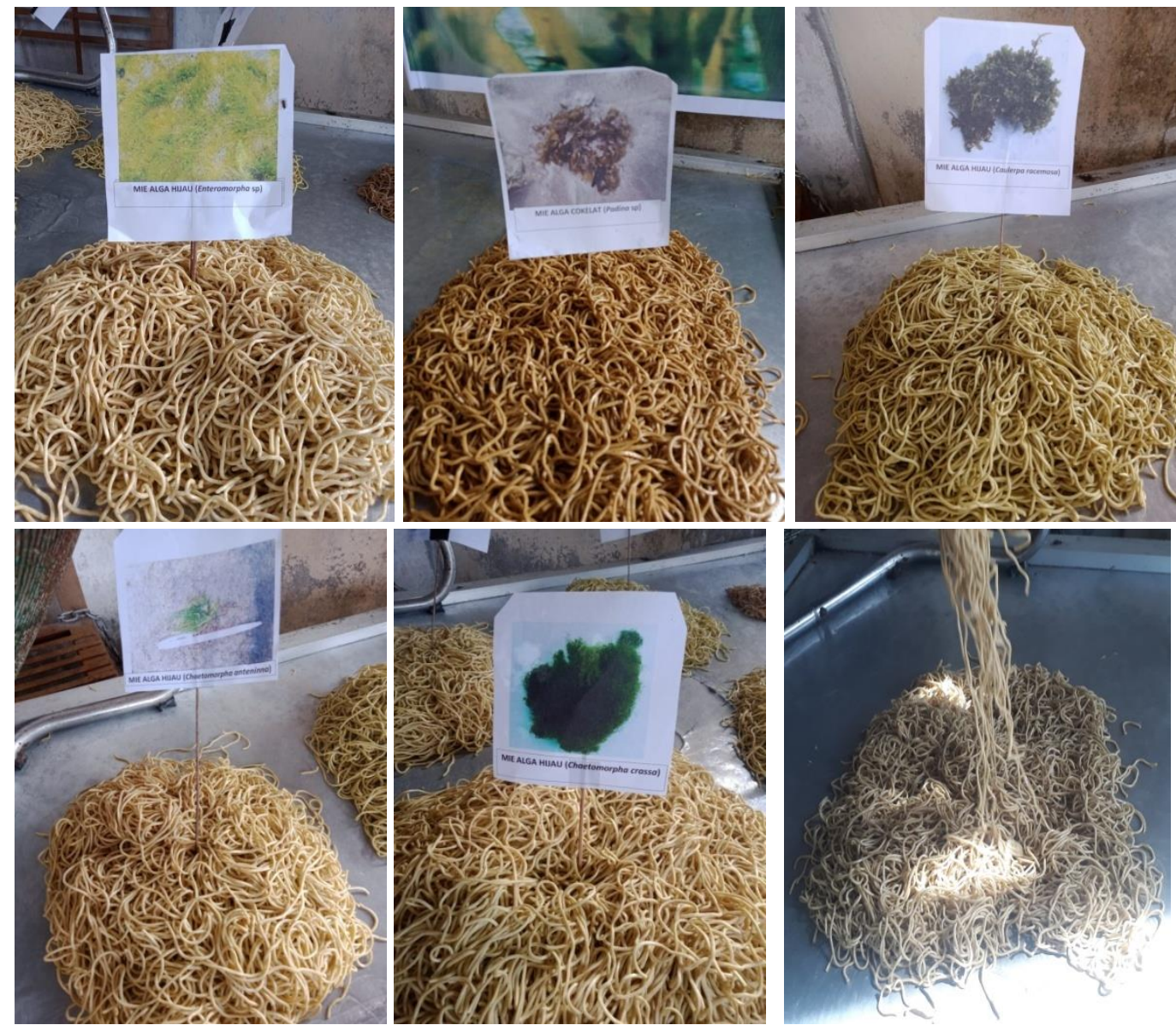

Gambar 5. Produk Mie Aceh pewarna Rumput Laut

\section{SIMPULAN}

Berdasarkan hasil dan pembahasan maka dapat disimpulkan bahwa kegiatan Pengabdian kepada masyarakat dengan melakukan pemberdayaan masyarakat lokal dalam pemanfaatan alga cokelat (Sargassum sp) sebagai pewarna alami mie Aceh meliputi tahapan pengambilan bahan baku rumput laut di wilayah Barat Selatan (BARSELA), uji coba pewarna alami yang berasal dari rumput laut, dan kegiatan sosialisasi dan pelatihan bagi masyarakat lokal. Output yang diharapkan dalam kegiatan pengabdian ini adalah adanya peningkatan pemahaman dan keterampilan bagi masyarakat terhadap pemanfaatan rumput laut asal Barat Selatan (BARSELA) Aceh sebagai Pewarna Alami. 


\section{UCAPAN TERIMA KASIH}

Dalam program kegiatan Pengabdian ini, Peneliti mengucapkan terima kasih kepada Bapak Syafrinizal sebagai mitra Program Kemitraan Masyarakat Stimulus (PKMS) yang memfasilitasi peralatan pembuatan mie Aceh. Selain itu, ucapan terima kasih kepada mahasiswa FPIK UTU yang membantu dalam proses pengabdian kepada Masyarakat ini. Kegiatan Pengabdian ini didanai oleh Kemenristek-DIKTI pada skim Program Kemitraan Masyarakat Stimulus (PKMS) dengan Nomor Kontrak 029/UN59.7/TL/2019.

\section{DAFTAR PUSTAKA}

Kementerian Kelautan dan Perikanan Republik Indonesia. 2003. Perdagangan makroalga laut. www.dkp.go.id

Critchley A, Ohno M, Largo D. 2006. The Seaweed Resources of the World. Amsterdam (NL): ETI.

Widyastuti S. 2009. Kadar alginat rumput laut yang tumbuh di perairan laut Lombok yang diekstrak dengan dua metode estraksi. J. Teknol Pertanian. 10(3): 144152. 